Research Article

\title{
Connection between Relationship Quality and Megaproject Success: Moderating Role of Contractual Functions
}

\author{
Dedong Wang $\left(\mathbb{D},{ }^{1,2}\right.$ Yongqiang $L u \mathbb{D}^{1},{ }^{1}$ and Shaoze Fang $\mathbb{D D}^{1}$ \\ ${ }^{1}$ School of Management Engineering, Shandong Jianzhu University, Jinan 250101, China \\ ${ }^{2}$ Shandong Co-Innovation Center of Green Building, Jinan 250101, China \\ Correspondence should be addressed to Yongqiang Lu; lyq19940326@163.com
}

Received 28 February 2019; Accepted 10 June 2019; Published 25 June 2019

Academic Editor: Mohammad R. Hosseini

Copyright (C) 2019 Dedong Wang et al. This is an open access article distributed under the Creative Commons Attribution License, which permits unrestricted use, distribution, and reproduction in any medium, provided the original work is properly cited.

Relational governance is critical to project success. The present study on relational governance fails to elaborate on the relation between relationship quality and project success. In line with social exchange theory, this paper presents an empirical research of Chinese megaprojects to explore the effect of social exchange factors on relationship quality. Particularly, this research investigated how mianzi (face) as a factor variable affects relationship quality in megaprojects. This work also divided contract functions into control, coordination, and adaptation to investigate the impact of these functions on the relationship between social exchange factors and mianzi (face) with relationship quality. Results corroborate the following points: (1) relationship quality has a significant effect on project success; (2) relationship quality is also significantly influenced by trust, reciprocity, commitment, and mianzi; and (3) regarding the moderating effects of contractual functions, the contractual control function has a positive influence on the relationship between trust, commitment, and relationship quality and has a negative influence on the relationship between mianzi and relationship quality. However, contractual control has no apparent effect on the relationship between reciprocity and relationship quality. The contractual coordination function has a positive effect on the relationship between trust, commitment, and relationship quality. The contractual adaptation function has a significant positive effect on the relationship between trust and relationship quality. These findings provide new insights into relationship governance, and suggestions for contractual function design are provided.

\section{Introduction}

Megaprojects refer to construction projects with an investment of more than 1 billion USD [1]. These projects are characterized by huge investment and high complexity. Megaproject construction usually takes several years to complete, involves multiple stakeholders, and affects millions of residents $[2,3]$. With rapid urbanization and economic development, the demand for infrastructure megaprojects, such as water and sewage, electricity, transportation, and telecommunications, in developing countries has increased in the past decades [4]. These projects occupy an important position in the national economy and profoundly affect social development [5]. However, the importance of megaprojects is in contrast with their low success rate in these countries $[1,6]$. As time passes, the overruns, delays, quality problems, safety accidents, and insufficient benefits of megaprojects remain inadequately resolved $[4,7]$. These disadvantages have adversely affected the further development of megaprojects.

Researchers have conducted extensive investigations on factors that affect megaproject success. Scholars have claimed that the failure of megaprojects lies in the relationships among project participants [8-10]. Given the different interests of participants, some of them likely exhibit opportunistic behavior to maximize their interest, which will lead to strained relations with other participants. Such a relationship among project participants commonly influences their cooperation level, which strongly affects the project outcome $[9,11,12]$. To improve the relationship between construction project participants, researchers have developed tools to support the management of relationships. Some researchers used the Analytic Hierarchy Process (AHP) method and Partnering Temperature Index (PTI) as 
tools to support the management of partnerships in the implementation process of construction projects [13-16]. Yeung also uses the Internet-based Computerized Partnering Performance Index System (CPPIS) to help end-users to identify problematic areas and critical success factors for achieving partnering excellence [17]. Also, Bayliss identified monthly partnership review sessions and the use of incentives as effective relationship management tools [18]. These studies show that studying the relationships among participants is necessary and feasible to improve the success rate of megaprojects.

Most researchers have studied relationships mainly from the perspective of relational governance and formal control [19]. Relational governance is based on relational exchange theory and uses relational contract to create valuable relationship [20]. Formal control entails contract provisions that stipulate the behavior of participants and allocate risks to guide participants in achieving the goals [21]. Although these two governance mechanisms exert a significant effect on relationship, existing research is inadequate. On one hand, factors that influence relationship have not been clarified and the relationship has not been discussed from a social exchange perspective. On the other hand, examining only the effect of contractual control function is insufficient. Except for control functions, the contract includes other important functions [22-24]. The effect of different contract functions on relationships should be analyzed. To supplement the deficiencies of previous research, we select social exchange factors that influence the relationship based on social exchange theory (SET). Mianzi, which has an important influence on relationship [25-27], is included in this research model. For the convenience of research on relationships, we introduce the concept of relationship quality into this study as a tool for measuring relationships.

The study aims to solve the following three questions:

RQ1: Does relationship quality between megaproject participants significantly affect project success?

RQ2: How do social exchange factors and mianzi affect the relationship quality of project participants?

RQ3: How do different contract functions affect the relationship between influencing factors and relationship quality?

Solving these questions expands the research on the influencing factors of relationship and help managers make timely adjustments regarding the relationship among participants in megaprojects. Studying the effect of various contractual functions on relationships can also aid in determining the functional design of the entire contract. To achieve these research objectives, we first review the relevant literature to develop a model. The proposed model has eight hypotheses that aim to test the effect of relationship influence factors on relationship quality and moderating of contractual different functions. We then introduce the research methodology, related data collection, and analysis. In the final part of the paper, we discuss the findings, draw conclusions, and provide relevant suggestions for future research.

\section{Literature Review and Hypothesis Development}

2.1. Megaproject Success and Relationship Quality. In the history of developing project success standards, the "iron triangle" of time, cost, and quality occupies crucial positions $[28,29]$. However, these parameters only represent a direct contribution to profits without considering whether the project has been properly implemented [30]. After the project is completed and handed over, the focus shifts from product manufacturing to value creation. Accordingly, the evaluation criteria of project success should be expanded. The criteria should include not only the process of the project products but also the operation results and benefits after project completion [31, 32]. In the multidimensional study of project success criteria, researchers have developed various models to measure project success. These models differentiate project success from project management success. The latter, which is also known as "project efficiency," depends primarily on whether the output is delivered according to time, cost, and functionality requirements [33]. By contrast, project success considers whether the project results are in line with the strategic objectives of the investment organization. This goal can be measured by the degree to which key stakeholders are satisfied with the extent to which the project achieves its strategic objectives.

This study selects the model of [34] to measure project success. The model of Khan et al. analyzes the literature of the past 40 years and integrates the literature on project success. In the model, the authors define the "iron triangle" as project efficiency, which is a dimension of project success. The model includes four other dimensions. The overall model consists of the following dimensions:

(1) Project efficiency

(2) Organizational benefits

(3) Project impact

(4) Stakeholder satisfaction

(5) Future potential

The definition of relationship quality originates from the relationship marketing literature [35]. Relationship quality can generally be described as the appropriateness or strength of the relationship formed between participants [36]. Relationship quality is a higher-order structure composed of several different but related dimensions and can be used as a tool for assessing the relationship between organizations $[35,37]$. In recent years, the concept of relationship quality has been introduced to the construction industry to evaluate the state of the relationship between two sides. The goals achieved in a megaproject are challenging and require participants to collaborate well to achieve them [38]. The multiple participants constitute a complex network of relationships, and the relationships formed among different participants can be strong or weak. High-quality relationships can effectively facilitate communication between participants and help participants exchange information and 
knowledge. Such a relationship can also reduce opportunistic behavior and maximize the joint action effect [39]. Project success often involves active cooperation and high relationship quality between project organizations [40]. By contrast, confrontational or deteriorating relationship between project parties often results in poor project performance $[12,41]$. Poor relationship between parties is considered an important reason for project failure. Following this discussion, we hypothesize the following:

Hypothesis 1 (H1). Relationship quality is positively related to project success.

\subsection{Social Exchange Factors and Relationship Quality.} Social exchange theory is a broad conceptual paradigm covering many social science disciplines [42]. The theory was originally proposed to analyze human behavior and has been applied to organizational behavior analysis [43]. This theory holds that people form in their social interactions social relationships that are exchanges and all human behaviors are affected by exchange activities that bring returns [44, 45]. Participants must abide by the principles of exchange in the exchange process. Trust is the basic principle of social exchange. In economic exchanges, less trust and more active supervision are generally involved, but social exchanges are commonly open and involve greater trust and flexibility [46]. In social interaction between megaprojects, trust, as the foundation and pillar of interorganizational communication, is an important investment for interorganizational communication. Past social exchange studies have extensively investigated and emphasized the principle of reciprocity. During relationship exchange, resources must be exchanged through the principle of reciprocity, which is the pillar of interpersonal and interorganizational relations [47]. The reputation of an organization that does not follow the principle of reciprocity can be damaged within the industry. However, the degree to which the principle of reciprocity is applied to organizations varies across different cultural backgrounds. In building of social exchange, participants must also invest in commitment. Commitment is an important part of the relationship exchange among organizations. Mutual commitment is the responsibility of enterprises and other partners, which constitutes the basis for the participants to jointly solve problems [48]. Considering the high uncertainty and risk of megaprojects, participants must strongly commit to social interactions for partners to have long-term cooperation intentions. Therefore, this study is based on SET to explore the effects of trust, reciprocity, and commitment on interorganizational relationship quality.

2.2.1. Trust and Relationship Quality. Sociologists emphasize the importance of trust in social interaction. Although experts believe that trust exists only in individuals, management researchers look into trust from an organizational level [49]. Trust refers to one party's expectation or belief that the other party's future behavior is beneficial to its interests $[50,51]$. When a project is in a highly trusted environment, "distortion" in information transmission can be reduced and communication between project participants can be promoted [52]. Similarly, trust is developed through communication and increase in communication can further enhance trust between participants [52]. Project organizations can leverage trust-based relationships to accomplish entire project goals [53]. From the perspective of SET, trust is the basic principle of social exchange and the pillar to maintaining the relationship between participating project organizations. Given that megaprojects are influenced by uncertainty and potential opportunistic behavior of partners, trust can create a good relationship atmosphere and is the basis for long-term cooperation success [52]. Therefore, trust is a key component of building and maintaining good partnerships [54]. Previous studies confirm that trust can consolidate key stakeholder relationship and significantly affect project success [55]. Based on the related literature, we hypothesize the following.

Hypothesis 2 (H2). Trust is positively related to the relationship quality among participants in a project.

\subsubsection{Reciprocity and Relationship Quality. Reciprocity} means that in the process of relationship exchange, an organization helps cooperative partners who face difficulties. Recipient organizations are obliged to repay the benefits when the beneficiary organizations also face difficulties [56, 57]. Reciprocity occurs because participants expect future benefit from their present reciprocity, even if they do not receive the expected benefit from the participants they helped at the moment. Reciprocity and altruism are fundamentally different [58]. Altruism behavior indicates unconditional good will [57]. If participants in a project have strong reciprocal intentions, then the existence of such intentions will greatly improve the prospects for cooperation. In megaprojects, high uncertainty and underlying opportunistic behavior will cast a shadow on the cooperation intentions of the parties. Reciprocity can be used as a powerful normative means to force project participants to rationally allocate project benefits to mitigate the effects of the above hazards. During relationship exchange, a partner must follow the principle of reciprocity. The reputation of the participant who violates the principle of reciprocity will be damaged, and the intention of other participants to cooperate with them will be weakened [59]. Therefore, we hypothesize the following:

Hypothesis 3 (H3). Reciprocity is positively related to the relationship quality among the participants in a project.

2.2.3. Commitment and Relationship Quality. Commitment is necessary for partners to build good relationships, as highly committed partners will try to balance short-term 
objectives with long-term objectives [60]. A cooperative relationship is based on mutual commitment [61]. Commitment provides the basis for cooperation among project participants and is an important variable that distinguishes social exchange from economic exchange [62]. From a behavior perspective, commitment is a critical act of establishing and maintaining a long-term relationship, which includes sacrificing short-term benefits in exchange for long-term benefits and investing in specific resources to maintain the relationship. From the perspective of attitude, commitment is the attitude of developing and maintaining a long-term relationship among partners [63]. If adequate commitment exists, then a partner willingly establishes a stable business relationship, which reduces the possibility of relationship dissolution. A high degree of commitment is necessary for successful cooperation. Therefore, we hypothesize the following.

Hypothesis 4 (H4). Commitment is positively related to the relationship quality among the participants in a project.

2.3. Mianzi and Relationship Quality. Chinese culture differs from Western culture in many ways. Confucian culture constitutes the main body of Chinese culture. Guanxi, mianzi, and harmony significantly affect the relationship development strategy $[64,65]$. As one of the most prominent cultural characteristics in Chinese culture, mianzi strongly influences the dynamics of interorganizational relationship in a project [66]. Mianzi is the social status of an organization and represents its influence on other organizations $[67,68]$. Each organization must have a certain amount of mianzi to maintain and expand its network of relationships and influence others. Losing mianzi means losing reputation and organizational dignity, which implies losing influence on others $[69,70]$. In Chinese culture, protecting the mianzi of oneself and others is crucial for maintaining good relationships. Under this premise, participants are asked to be less confrontational and direct in dealing with divergence to save their mianzi and that of other participants [71]. This situation encourages participants to use a compromised and stabilized way in dealing with conflicts to protect the harmonious relationship among organizations throughout the project cycle. From this discussion, we hypothesize the following.

Hypothesis 5 (H5). Mianzi is positively related to the relationship quality among the participants in a project.

2.4. Moderating Variables. Megaprojects face greater complexity and uncertainty than ordinary projects $[6,72]$. These characteristics determine that the overall interests of megaprojects are more susceptible to damage from opportunistic behavior. Contracts, as an effective formal mechanism, can mitigate the hazards between organizations. In addition, contracts can protect the interests of all parties from relevant provisions and reliably and accurately coordinate the economic exchanges among participants. The functions of the contract are diverse. At present, research on megaproject contracts has gradually shifted from a single-contract control dimension to a multidimensional contract function. The contractual functions are divided into control, coordination, and adaptation $[22,23]$.

\subsubsection{Moderating Effect of Contractual Control Function.} The contract control function is mainly to protect the investment from the opportunism of the participants. On the one hand, the provisions on how to handle disputes after the party stipulated in the contract belongs to the contractual control function. On the other hand, the contractual control function is reflected in the setting of incentive and penalty provisions $[73,74]$. The incentive provision encourages the project participants to take actions that are beneficial to the overall interests of the project. Also, penalty provisions limit the behavior of the project participants to protect the overall interests of the project [24]. The third-party arbitration, oversight, and dispute resolution rights set out in the contract terms are considered terms of the control function [75]. The effect of trust on the relationships among the various parties can be enhanced with high contractual control because it has a more rational distribution of benefits than low contractual control. At the same time, incentives can encourage participants to take the initiative to conduct reciprocal behaviors. Similarly, penalty clauses can prevent participants from not engaging in reciprocal behavior to avoid losses. The high control function can strengthen the initiative of the participants to make sufficient commitment through reasonable resolution of disputes. This agreement strengthens the connection between the parties. However, in the Chinese cultural context, the contract control provision is considered a way of "not giving mianzi" [76]. Accordingly, we hypothesize the following.

Hypothesis $6 a(\mathrm{H} 6 \mathrm{a})$. Contractual control positively affects the relationship between trust and relationship quality.

Hypothesis $66(\mathrm{H} 6 b)$. Contractual control negatively affects the relationship between reciprocity and relationship quality.

Hypothesis $6 c(\mathrm{H} 6 \mathrm{c})$. Contractual control positively affects the relationship between commitment and relationship quality.

Hypothesis $6 d(H 6 d)$. Contractual control negatively affects the relationship between mianzi and relationship quality.

\subsubsection{Moderating Effect of Contractual Coordination} Function. The contractual coordination provisions include clear task descriptions, communication procedures, and interpretation terms $[77,78]$. The task description 
provision objectively describes how to complete the task. The provision reduces the misunderstanding of the participants in the cooperation process $[21,23]$. Communication procedures and interpretation terms enhance the speed and accuracy of information spreading, which helps project participants make timely and accurate judgments $[51,79]$. The highly coordination function enhances the initiative of participating organizations to their partners' commitments compared with low coordination functions [80]. The increase in the speed of information spreading and the increase in communication procedures enable participating organizations to understand the changes in their projects that are relevant to their interests as early as possible, which enhances the trust of participating organizations in their partners [81]. Accordingly, we hypothesize the following.

Hypothesis $7 a(\mathrm{H} 7 \mathrm{a})$. Contractual coordination positively affects the relationship between trust and relationship quality.

Hypothesis $7 b(H 7 b)$. Contractual coordination positively affects the relationship between commitment and relationship quality.

\subsubsection{Moderating Effect of Contractual Adaptation Function.} The contractual adaptation function is reflected in the provision that deals with the uncertainty changes in a project, such as price adjustment, procedures for handling unexpected situations, and the provision for force majeure [82]. By stipulating the principles for handling emergencies or specific solutions, all participants can take timely and consistent actions in addressing emergencies in the project and help all participants better adapt to the interference in the transaction process to avoid possible dispute among participants [83]. The highly contractual adaptation function provides detailed procedures for determining uncertain events and reducing uncertainty of participant behavior [84]. In the cases of reduced participation and inaccurate behavior, the participants have a relatively clear understanding of their partner's future behavior, which enhances the trust of the partners and promotes the fluency of cooperation among all participants [78]. Following the above discussion, we hypothesize the following.

Hypothesis $8 a(\mathrm{H} 8 \mathrm{a})$. Contractual adaptation positively affects the relationship between trust and relationship quality.

Figure 1 exhibits the research model.

\section{Methodology}

3.1. Method. This study used the deductive method to commit general statements rather than individual or case studies. As the hypotheses are established based on relevant theories and tested by collecting data for analysis, this study used quantitative analysis to conduct research.

In this deductive study, we used an empirical epistemological position and questionnaires for data collection. We chose partial least squares structural equation model (PLS-SEM) rather than CB-SEM (covariance-based structural equation model) to analyze data. We chose PLS-SEM for two reasons. First, given that the research is exploratory, our model has not been established in previous research. For the model that is in the exploration stage and needs further development, PLS-SEM is better than other methods [85]. Second, PLS-SEM can be applied on a smaller sample size than CB-SEM [85]. In this study, multigroup analysis was needed to evaluate the moderating variables. After grouping data, the sample of the single group was small, and thus, analysis was performed by PLS-SEM.

3.2. Sample and Data Collection. All the selected projects in this study are from China. The selection mainly involves two criteria. First, for the selection of megaprojects, we set projects with an investment of over 1 billion USD (approximately 6.9 billion RMB) according to the definition of a megaproject by Flyvbjerg [1], as the standard for projects that were selected. Second, as this research investigated the relationship between organizations, we chose persons who held senior positions in companies and projects as respondents, such as company directors or project managers. These individuals have a comprehensive understanding of the relationship among participating organizations [40].

To facilitate the respondents' understanding of the questionnaire and ensure survey accuracy, we adopted the translation of English questions into Chinese by using the parallel-translation method. Before issuing the questionnaire to the respondents, we submitted the Chinese questionnaire to two experts and 10 practitioners who have more than 15 years of experience for review. The 10 practitioners consisted of two owners, two supervisors, three designers, and three contractors.

During data collection, we selected 36 projects for conducting on-the-spot investigations in Jiangsu and Shandong. At the same time, we used snowballing to maximize the number of respondents. All respondents were required to find other qualified personnel who meet the two criteria set forth above. The results of the final data were collected from China's Zhejiang, Henan, Shandong, Jiangsu, Anhui, Hebei, and Hubei provinces. Of the 526 questionnaires sent out, we obtained 288 received responses, for a response rate of $54.7 \%$. After eliminating invalid questionnaires, 256 questionnaires from 89 projects were available for analysis. Three ways of questionnaire collection were utilized throughout the data collection process, namely, on-the-spot collection, online survey, and email. Answers from the three types of responses were compared through a one-way analysis of variance, revealing no significant differences at the 0.05 significance level. Hence, data from all three sources were used for the analysis without distinction. The entire data collection process took place from May to September 2018. 


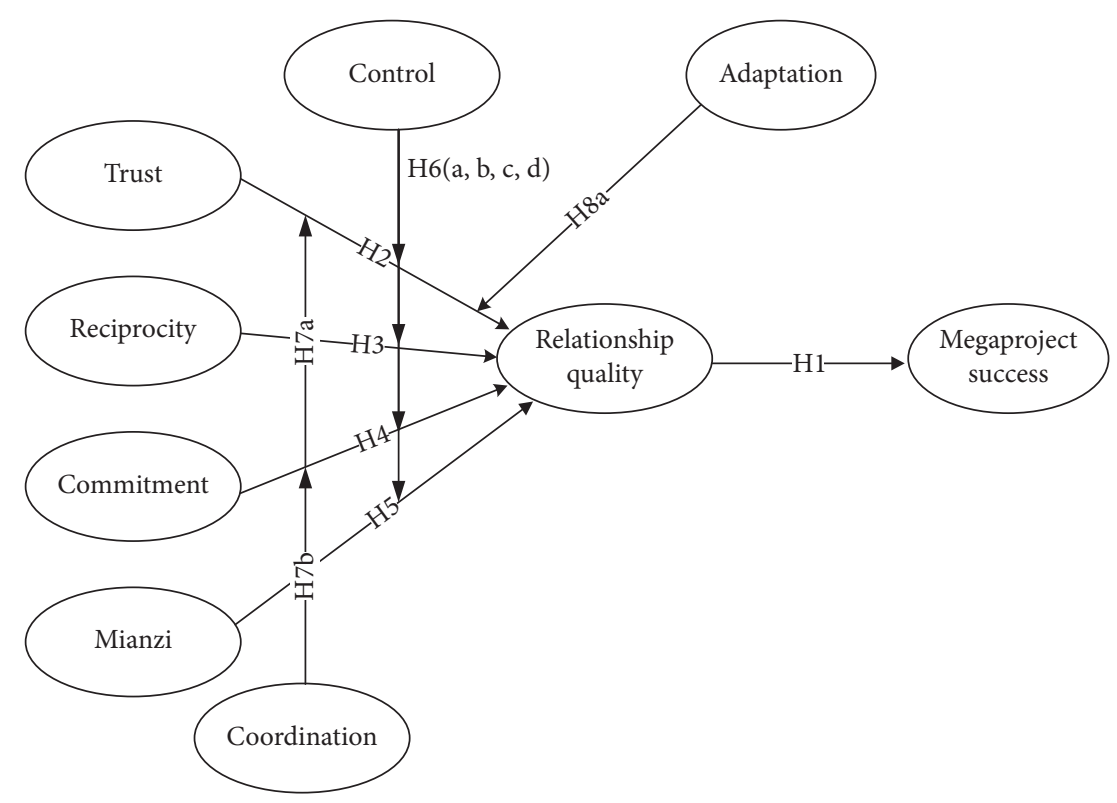

FIGURE 1: Research model and hypotheses.

In this study, the personnel to be surveyed were classified according to experience and the respondent's role. Projects were classified according to investment scale. Table 1 lists the specific classifications.

3.3. Measurements. Questionnaire items came from existing references about relationship management and project governance. To meet our research needs and the suggestions of experts, we modified the settings of items in extant sources. In the questionnaire survey, all constructs were measured reflectively with multiple items on a seven-point Likert scale (e.g., $1=$ strongly disagree and $7=$ strongly agree).

Six items on trust (TR1-TR6) [86, 87] were used to test the trust degree of each participant throughout the project cycle. Four items on reciprocity (RE1-RE4) were used to test reciprocity intention among organizations [88]. Three items (CO1-CO3) [89] on commitment were used to measure the degree of commitment between organizations. Mianzi was measured by three items (MZ1-MZ3) [90] in an attempt to test the importance of mianzi as a special factor in the influence on relationship quality. The assessment of relationship quality comprised four items (RQ1-RQ4) [40], and the megaproject success was measured by five items (PS1-PS5) [34]. In terms of moderating variables, the functions of complex contract terms in megaprojects were mainly regarded as three aspects [24]. According to You's research, the contractual control function consisted of four items (CR1-CR4), the coordination function was composed of five items (CN1-CN5), and the adaptation function comprised four items (AD1-AD4). Table 2 presents all the constructs and their source references.

\section{Data Analysis and Results}

4.1. Measurement Model. To estimate the reliability and validity of the model, we assessed the performance based on
TABle 1: Classification of respondents.

\begin{tabular}{lccc}
\hline & Type & Number & $\begin{array}{c}\text { Percentage } \\
(\%)\end{array}$ \\
\hline \multirow{3}{*}{ Experience } & 3-5 years & 26 & 10.2 \\
& 5-10 years & 51 & 19.9 \\
& 11-15 years & 64 & 25.0 \\
& 16-20 years & 78 & 30.5 \\
Respondent's & Constructor firms & 87 & 14.5 \\
role & Supervisor firms & 34 & 30.5 \\
& Consultant firms & 36 & 13.3 \\
& Others & 21 & 8.2 \\
Investment & 7-10 billion RMB & 27 & 30.3 \\
scale & 20-20 billion RMB & 26 & 29.2 \\
& 30-50 billion RMB & 17 & 19.1 \\
& More than 50 billion & 12 & 13.5 \\
& $\quad$ RMB & 7 & 7.8 \\
\hline
\end{tabular}

Note. $1 \mathrm{USD}=6.9 \mathrm{RMB}$.

internal consistency, indicator reliability, convergent validity, and discriminant validity. Data analysis contends that all Cronbach's $\alpha$ value and factor loadings are more than 0.7 . This result indicates that the model has reasonable internal consistency and indicator reliability. Convergent validity can be tested by examining the values of the average variance extracted (AVE) and the composite reliability (CR). Table 3 provides these values. These outcomes fully meet the requirements that CR value should be greater than 0.7 and AVE value should be greater than 0.5 [85]. Satisfactory discriminant validity can be confirmed from the square root of AVE, which should be greater than its highest off-diagonal correlation with any other construct [85]. Table 4 confirms that the values meet the all requirements for discriminant validity. 
TABLE 2: Measures of constructs.

\begin{tabular}{|c|c|c|}
\hline Construct & Description of measurement items & $\begin{array}{c}\text { Key } \\
\text { source(s) }\end{array}$ \\
\hline Trust & $\begin{array}{l}\text { TR1: We believe the other party can keep their word throughout the life of the project. } \\
\text { TR2: We feel confident that the other participants have high levels of integrity and honesty. } \\
\text { TR3: We believe the project engineers and other technical people are competent at what they are doing. } \\
\text { TR4: We trust that the project participants can fulfill contractual agreements. } \\
\text { TR5: We are certain that the other participants are capable of performing their tasks. } \\
\text { TR6: We believe that the other participants could meet the requirements of the project in technology and } \\
\text { management. }\end{array}$ & {$[86,87]$} \\
\hline Reciprocity & $\begin{array}{l}\text { RE1: The practice of "give and take" of favors is a key part of the relationship between our partners and us. } \\
\text { RE2: We have an obligation to help our business partners. } \\
\text { RE3: We would feel embarrassed if we were unable to provide a requested favor to a partner. } \\
\text { RE4: It is bad business not to return the favors of partners. }\end{array}$ & [88] \\
\hline Commitment & $\begin{array}{l}\text { CO1: Project partners are willing to make sacrifices to help us. } \\
\text { CO2: Project partners are willing to continue a rewarding business relationship with us. } \\
\text { CO3: Project partners are willing to spend higher amount of time and effort with us. } \\
\text { MZ1: Both our partners and our team care for mianzi. }\end{array}$ & [89] \\
\hline Mianzi & $\begin{array}{l}\text { MZ2: The more respect we receive, the more mianzi we have. } \\
\text { MZ3: We give mianzi to our partner, and they also give mianzi to us. } \\
\text { RQ1: Our partners and our team are very fluent in knowledge sharing. }\end{array}$ & {$[90]$} \\
\hline $\begin{array}{l}\text { Relationship } \\
\text { quality }\end{array}$ & $\begin{array}{c}\text { RQ2: Our partners and our team are very fluent in communication. } \\
\text { RQ3: Our partners and our team are very fluent in solving problems together. } \\
\text { RQ4: We have common goals with our partners. }\end{array}$ & {$[40]$} \\
\hline $\begin{array}{l}\text { Project } \\
\text { success }\end{array}$ & $\begin{array}{l}\text { PS1: The project was successful in terms of the project efficiency of the work. } \\
\text { PS2: The project was successful in meeting organizational benefits. } \\
\text { PS3: The project was successful in the impact on potential beneficiaries. } \\
\text { PS4: The project was successful in project team satisfaction. } \\
\text { PS5: The project was successful in providing motives for other projects in the future. } \\
\text { CR1: The contract defines the rights of both parties specifically. }\end{array}$ & {$[34]$} \\
\hline $\begin{array}{l}\text { Contractual } \\
\text { control }\end{array}$ & $\begin{array}{l}\text { CR2: The contract specifically stipulates how the party awarding the contract monitors the contractor. } \\
\text { CR3: The contract specifically stipulates the rights entitled to one party if the other party breaches the contract. } \\
\text { CR4: The contract specifically stipulates provisions on early termination after breaching the contract. } \\
\text { CN1: The contract specifically stipulates how the parties send written documents. }\end{array}$ & {$[24]$} \\
\hline $\begin{array}{l}\text { Contractual } \\
\text { coordination }\end{array}$ & $\begin{array}{l}\text { CN1: The contract specifically stipulates how the parties send written documents. } \\
\text { CN2: The contract provides detailed technical specifications and drawings. } \\
\text { CN3: The contract specifically stipulates the quality acceptance procedures. } \\
\text { CN4: The contract specifically stipulates the personnel qualifications or dispatching issues. } \\
\text { CN5: The contract specifically defines the division of labor of both parties. }\end{array}$ & {$[24]$} \\
\hline $\begin{array}{l}\text { Contractual } \\
\text { adaptation }\end{array}$ & $\begin{array}{l}\text { AD1: The contract specifically stipulates the adjustments due to changes in cost. } \\
\text { AD2: The contract specifically stipulates the adjustments due to changes in exchange rates. } \\
\text { AD3: The contract specifically stipulates the handling procedures if geological conditions, against which an } \\
\text { experienced contractor could not reasonably be expected to react, should arise. } \\
\text { AD4: The contract specifically stipulates the handling procedures if climatic conditions, against which an } \\
\text { experienced contractor could not reasonably be expected to react, should arise. }\end{array}$ & {$[24]$} \\
\hline
\end{tabular}

Note. $\mathrm{TR}=$ trust $\mathrm{RE}=$ reciprocity; $\mathrm{CO}=$ commitment; $\mathrm{MZ}=$ mianzi; $\mathrm{RQ}=$ relationship quality; $\mathrm{CR}=$ contractual control; $\mathrm{AD}=$ contractual adaptation; $\mathrm{CN}=$ contractual coordination; $\mathrm{PS}=$ project success .

TABLE 3: Measurement reliability and convergent validity assessment.

\begin{tabular}{lccc}
\hline Construct & AVE & CR & Cronbach's alpha values \\
\hline TR & 0.501 & 0.857 & 0.801 \\
RE & 0.556 & 0.862 & 0.802 \\
CO & 0.591 & 0.852 & 0.771 \\
MZ & 0.697 & 0.873 & 0.784 \\
RQ & 0.517 & 0.842 & 0.765 \\
CR & 0.798 & 0.940 & 0.915 \\
AD & 0.706 & 0.906 & 0.860 \\
CN & 0.565 & 0.850 & 0.785 \\
PS & 0.593 & 0.875 & 0.838 \\
\hline
\end{tabular}

4.2. Structural Model. In this study, the structural model includes relationship quality and project success. The main criteria for evaluating structural models are via path coefficients and the coefficient of determination $\left(R^{2}\right)$. We employed PLS algorithm with 300 iterations to obtain path coefficients and bootstrapping analysis with 
TABLE 4: Correlations of latent variables and evidence of discriminant validity.

\begin{tabular}{|c|c|c|c|c|c|c|c|c|c|}
\hline Construct & TR & $\mathrm{RE}$ & $\mathrm{CO}$ & $\mathrm{MZ}$ & RQ & CR & $\mathrm{CN}$ & $\mathrm{AD}$ & PS \\
\hline TR & 0.708 & & & & & & & & \\
\hline $\mathrm{RE}$ & 0.470 & 0.746 & & & & & & & \\
\hline $\mathrm{CO}$ & 0.365 & 0.496 & 0.769 & & & & & & \\
\hline $\mathrm{MZ}$ & 0.624 & 0.530 & 0.665 & 0.835 & & & & & \\
\hline RQ & 0.608 & 0.529 & 0.519 & 0.585 & 0.719 & & & & \\
\hline CR & 0.404 & 0.287 & 0.382 & -0.432 & 0.463 & 0.893 & & & \\
\hline $\mathrm{CN}$ & 0.383 & 0.502 & 0.351 & 0.443 & 0.469 & -0.446 & 0.752 & & \\
\hline $\mathrm{AD}$ & 0.477 & 0.473 & 0.414 & 0.488 & 0.491 & -0.381 & 0.456 & 0.840 & \\
\hline PS & 0.320 & 0.300 & 0.233 & 0.433 & 0.450 & 0.290 & 0.235 & 0.263 & 0.770 \\
\hline
\end{tabular}

5000 subsamples to test the significance of the path coefficients.

The structural model accounts for $42.2 \%$ of the variance in relationship quality and $49.3 \%$ of the variance in project success. These $R^{2}$ values demonstrate the predictive validity of the model. Figure 2 presents the results of the model.

4.3. Hypothesis Testing. The result in Table 5 demonstrates that relationship quality exerts a significantly positive effect on project success $\left(\beta_{1}=0.649, t=18.733\right)$; that is, $\mathrm{H} 1$ is supported. In addition, Table 5 also shows that a significant positive relationship exists between trust and relationship quality $\left(\beta_{2}=0.603, t=6.972\right)$, reciprocity and relationship quality $\left(\beta_{3}=0.256, t=3.599\right)$, commitment and relationship quality $\left(\beta_{4}=0.342, t=3.706\right)$, and mianzi and relationship quality $\left(\beta_{5}=0.301, t=4.197\right)$. Hence, $\mathrm{H} 2, \mathrm{H} 3, \mathrm{H} 4$, and $\mathrm{H} 5$ are supported by the results of the data.

For the moderating effect of contractual functions, we divided the collected samples into 97 low-contractual control samples and 159 high-contractual control samples according to the median score of the contractual control function. Table 6 shows the analysis results. Under high contractual control, the path coefficients of $\mathrm{H} 2, \mathrm{H} 4$, and $\mathrm{H} 5$ are significantly changed compared with those under low contractual control. Therefore, this outcome supports H6a $(t=2.262)$, H6c $(t=2.437)$, and H6d $(t=3.561)$. As listed in Table 6, H6b $(t=1.032)$ is not supported. This result means that the improvement of the control function has no significant effect on reciprocity and relationship quality.

We divided the collected samples into 110 low-contractual coordination samples and 146 high-contractual coordination samples according to the median score of the contract coordination function. The analysis results in Table 7 reveal that $\mathrm{H} 7 \mathrm{a}(t=2.597)$ and $\mathrm{H} 7 \mathrm{~b}(t=1.986)$ are supported by data results.

Finally, we divided the collected samples into 108 lowcontractual coordination samples and 148 high-contractual adaptation samples according to the median score of the contract adaptation function. Table 8 shows the analysis results, and $\mathrm{H} 8 \mathrm{a}(t=2.898)$ is supported.

\section{Discussion}

5.1. Effect of Relationship Quality on Project Success. Through H1, this study confirms that the relationship quality between participants has significant positive effect on project success. The research question RQ1 can be answered. This result is similar to the conclusion of [12]. Compared with other types of projects, megaprojects face higher uncertainty and its participants are more likely to take opportunistic behavior. High-quality relationships can effectively improve the communication of knowledge and information. When the information and knowledge of all participants in the project spread quickly and accurately between organizations, the communication can reduce the damage of environmental uncertainty to cooperation and reduce the possibility of participants taking opportunistic behavior. This result is helpful for improving the project success rate. In addition, participants can use the relationship quality as a testing tool for cooperation level. By detecting the relationship quality, actions can be taken in time to make up for problems in the cooperation process.

5.2. Effect of Social Exchange Factors and Mianzi on Relationship Quality. By analyzing the effect of social exchange factors and mianzi on relationship quality, RQ2 was answered. As hypothesized in $\mathrm{H} 2, \mathrm{H} 3$, and $\mathrm{H} 4$, social exchange factors have an important effect on relationship quality. This result means that to establish high-quality relationship, participants must invest sufficient attention in these social exchange factors to create a state of high trust, reciprocity, and commitment. Trust is the initial belief that participants are willing to take risks to build partnerships with other participants. Without trust, project-related organizations will not enter risk-filled projects, especially megaprojects with severely higher risk. Reciprocity is the basis for building partnerships among participants. Participants who do not follow the principle of reciprocity will find difficulty in maintaining long-term relationships with others. Moreover, reciprocity can reduce the effect of uncertainty on the relationship between participants. Wu et al. [89] found that reciprocity has a great effect on the information exchange between participants. This outcome is similar to the results of the current research that reciprocity has a positive effect on relationship quality. Commitment is the intention of participants to actively establish a stable business relationship, and a high degree of commitment can reduce the possibility of relationship dissolution. Without mutual commitment, a relationship will experience difficulty in relation to stabilizing and lasting for a long time in project implementation. An important addition to this study for relationship research is that megaprojects should consider 


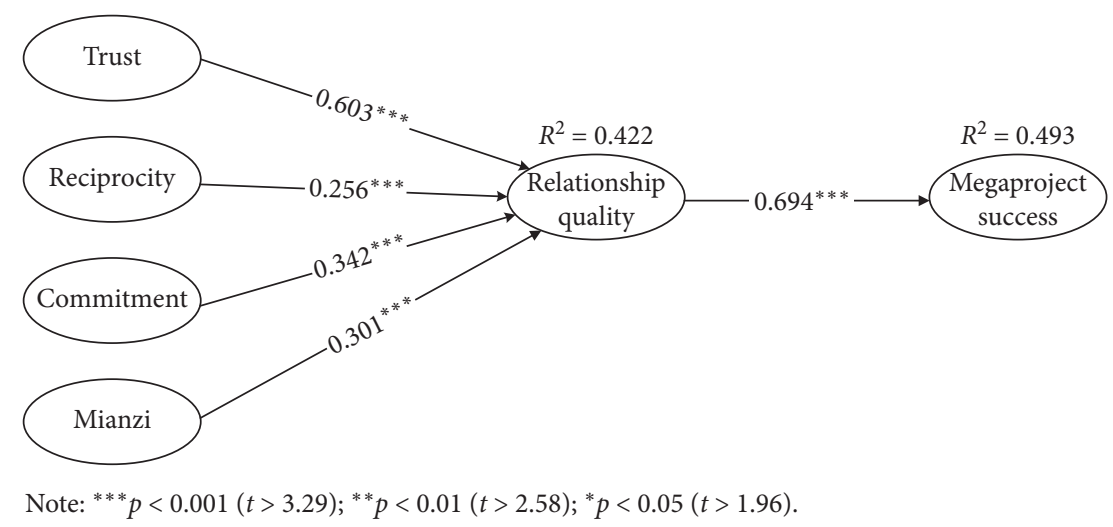

FIgURe 2: Results of PLS analysis for the structural model.

TABLE 5: Result of hypothesis testing.

\begin{tabular}{lccr}
\hline Hypothesis & Path coefficient & $t$ value & Result \\
\hline $\mathrm{H} 1: \mathrm{RQ} \longrightarrow \mathrm{PS}$ & $0.649^{\mathrm{c}}$ & 18.733 & Supported \\
$\mathrm{H} 2: \mathrm{TR} \longrightarrow \mathrm{RQ}$ & $0.603^{\mathrm{c}}$ & 6.972 & Supported \\
$\mathrm{H} 3: \mathrm{RE} \longrightarrow \mathrm{RQ}$ & $0.256^{\mathrm{c}}$ & 3.599 & Supported \\
$\mathrm{H} 4: \mathrm{CO} \longrightarrow \mathrm{RQ}$ & $0.342^{\mathrm{c}}$ & 3.706 & Supported \\
$\mathrm{H} 5: \mathrm{MZ} \longrightarrow \mathrm{RQ}$ & $0.301^{\mathrm{c}}$ & 4.197 & Supported \\
\hline Note. ${ }^{\mathrm{a}} p<0.05(t>1.96),{ }^{\mathrm{b}} p<0.01(t>2.58)$, and ${ }^{\mathrm{c}} p<0.001(t>3.29)$.
\end{tabular}

the effect of one's national cultural background on the relationship between project participants. The empirical result supports H5. As a special factor in the Chinese context, mianzi exerts crucial influence on relationship quality. "Give mianzi" is seen as an important way to reduce conflict and enhance cooperation between participants. Moreover, "give mianzi" means a harmonious solution between participants in conflict. By contrast, "not giving mianzi" means not paying attention to the relationship between the participants. This action will have obvious damage to the dignity and influence of the partners. Therefore, project participants should maximize the tool of "mianzi" to maintain the relationship network.

\subsection{Effect of Moderating Variable}

5.3.1. Moderating Effect of Contractual Control Function. Given H6a and H6b, the results prove that contractual control positively moderates the relationship among trust, commitment, and relationship quality. This finding is partly due to the high degree of control provisions and clarification of the reward and penalty system. This system enhances the awareness of fulfilling the contract among participants and increases the initiative of participants in social exchange. Consequently, the influence of trust and commitment enhances relationship quality.

By contrast, for H6d, the results show that the improvement of contractual control function will suppress the influence of mianzi on relationship quality. In Chinese cultural context, too many control provisions can be considered as "not giving mianzi" to other participants. Such practice will leave a negative impression among participants, such as difficulty in communicating and getting along. Such action will increase the barriers to cooperation and the possibility of conflicts and litigations among participants.

The results of the data do not support H6c. The effect of high control on the relationship between reciprocity and relationship quality does not change significantly compared with the low control scenario. This situation can be explained by noneffect of the enhancement of the contract control function on reciprocal intentions of the participants in the construction of the project. Moreover, the reciprocal behavior between the participants during the construction of project will not be affected. However, a high degree of control has a negative impression on all participants, thereby affecting the expectation of the two sides for cooperation and the initiative of both to take reciprocal actions in the next cooperation venture.

\subsubsection{Moderating Effect of Contractual Coordination} Function. The empirical result supports $\mathrm{H} 7 \mathrm{a}$ and $\mathrm{H} 7 \mathrm{~b}$. High-contractual coordination functions have a positive effect on the relationship of trust, commitment, and relationship quality. This outcome is based on the contractual coordination function enhancing the information exchange among participants as well as improving the understanding of one another's capabilities and work progress [91]. Hence, task ambiguity and information asymmetry are reduced among participants. This condition reduces barriers to fulfilling commitments and enhancing trust of participants in the social exchange process. Subsequently, the influence of trust and commitment enhances relationship quality.

\subsubsection{Moderating Effect of Contractual Adaptation Function.}

For H8a, the results confirm that the contractual adaptation has positive moderating effect on trust and relationship quality. That is, the adaptation provision provides treatment methods and principles after the incident. The possibility of the participants taking concerted action after incidents occur increases, and disputes during relationship management are reduced. Therefore, the contractual adaptation function can affect the role of trust in the social exchange process and improve the quality of the relationship among the participants. 
TABLe 6: PLS analysis of different levels of contractual control.

\begin{tabular}{lccccr}
\hline \multirow{2}{*}{ Hypothesis } & \multicolumn{2}{c}{ Low control $(n=97)$} & \multicolumn{2}{c}{ High control $(n=159)$} & Difference in path coefficient \\
& Path coefficient & $t$ value & Path coefficient & $t$ value & \\
\hline H6a: $\mathrm{TR} \longrightarrow \mathrm{RQ}$ & $0.487^{\mathrm{c}}$ & 6.275 & $0.675^{\mathrm{c}}$ & 9.713 & $0.188^{\mathrm{a}}$ \\
$\mathrm{H} 6 \mathrm{~b}: \mathrm{RE} \longrightarrow \mathrm{RQ}$ & $0.232^{\mathrm{b}}$ & 2.876 & $0.288^{\mathrm{c}}$ & 3.798 & 0.056 \\
$\mathrm{H} 6 \mathrm{c}: \mathrm{CO} \longrightarrow \mathrm{RQ}$ & $0.250^{\mathrm{b}}$ & 2.601 & $0.394^{\mathrm{c}}$ & 3.765 & $0.144^{\mathrm{a}}$ \\
$\mathrm{H} 6 \mathrm{~d}: \mathrm{MZ} \longrightarrow \mathrm{RQ}$ & $0.384^{\mathrm{c}}$ & 4.738 & $0.207^{\mathrm{a}}$ & 2.246 & $-0.177^{\mathrm{c}}$ \\
\hline
\end{tabular}

Note. ${ }^{\mathrm{a}} p<0.05(t>1.96),{ }^{\mathrm{b}} p<0.01(t>2.58)$, and ${ }^{\mathrm{c}} p<0.001(t>3.29)$.

TABLE 7: PLS analysis of different levels of contractual coordination.

\begin{tabular}{lcccrr}
\hline \multirow{2}{*}{ Hypothesis } & \multicolumn{2}{c}{ Low coordination $(n=110)$} & \multicolumn{2}{c}{ High coordination $(n=146)$} & Difference in path coefficient \\
& Path coefficient & $t$ value & Path coefficient & $t$ value & \\
\hline H7a: $\mathrm{TR} \longrightarrow \mathrm{RQ}$ & $0.415^{\mathrm{c}}$ & 5.796 & $0.643^{\mathrm{c}}$ & 6.748 & $0.228^{\mathrm{a}}$ \\
$\mathrm{H7b}: \mathrm{CO} \longrightarrow \mathrm{RQ}$ & $0.182^{\mathrm{a}}$ & 2.052 & $0.329^{\mathrm{c}}$ & 3.927 & $0.145^{\mathrm{a}}$ \\
\hline
\end{tabular}

Note. ${ }^{\mathrm{a}} p<0.05(t>1.96),{ }^{\mathrm{b}} p<0.01(t>2.58)$, and ${ }^{\mathrm{c}} p<0.001(t>3.29)$.

TABle 8: PLS analysis of different levels of contractual adaptation.

\begin{tabular}{|c|c|c|c|c|c|c|}
\hline \multirow{2}{*}{ Hypothesis } & \multicolumn{2}{|c|}{ Low adaptation $(n=108)$} & \multicolumn{2}{|c|}{ High adaptation $(n=148)$} & \multirow{2}{*}{ Difference in path coefficient } & \multirow{2}{*}{$t$ value } \\
\hline & Path coefficient & $t$ value & Path coefficient & $t$ value & & \\
\hline H8a: $\mathrm{TR} \longrightarrow \mathrm{RQ}$ & $0.417^{\mathrm{c}}$ & 4.435 & $0.604^{\mathrm{c}}$ & 7.661 & $0.186^{\mathrm{b}}$ & 2.898 \\
\hline
\end{tabular}

In this study, after analyzing the moderating of the contract functions, RQ3 has been answered.

\section{Conclusions and Implications}

6.1. Theoretical Implications. This study incorporates social exchange and contractual functional factors into the research model of relationship quality and project success and contributes to the megaproject management knowledge system. First, the empirical analysis demonstrates that the interorganizational relationship quality exerts significant positive effect on project success. Increasing the project success rate can start with cultivating and maintaining highquality relationships between organizations. Second, according to SET, we examined the effect of trust, reciprocity, and commitment on relationship quality. The results prove that trust, reciprocity, and commitment as social exchange factors have significant positive effect on relationship quality. Interorganizational interaction among megaprojects is not limited to economic exchanges, as social exchange plays a key part as well. The cultivation of the relationship among megaprojects depends to a large extent on the smooth progress of social interaction among organizations. Participating organizations must invest in social exchange factors to ensure that the organization's social interaction goes smoothly. Third, in addition to considering the factors in SET, this study reports that mianzi has a significant effect on interorganizational relationship. This result shows that in the process of social interaction between organizations, the effects of cultural factors of the project location should be considered. This idea is an important extension point of SET. Fourth, this study focuses on the different effects of contractual functions on relationship quality. This study reveals that three different contractual functions have a moderating effect on the relationship among social exchange factors, mianzi, and relationship quality. The results confirm that the contractual control function can positively moderate the relationship among trust, commitment, and relationship quality but has a negative effect on the relationship between mianzi and relationship quality. The contractual coordination function has positive moderating effect on the relationship among trust, commitment, and relationship quality. The contract adaptation function plays a positive role in the relationship between trust and relationship quality. Ensuring the relationship quality in complex contracts in megaprojects requires proper allocation of contract functions in the contract terms. Clear contract provisions can assure that high relationship quality is maintained as much as possible.

6.2. Managerial Implications. This study has managerial implications. First, in the social interaction of project participants, attention should be paid to the influence of mianzi factors on social interaction among organizations. Participants should actively protect themselves and others' mianzi to promote the development of social interaction processes and relationships. Megaprojects often involve participants from multiple countries. If participants in other countries can notice the influence of mianzi on Chinese projects, this observation will play a key role in enhancing the relationship among project participants. Secondly, the research has management significance for contract drafting and functional design. If the person drafting the contract changes the design of the contract function, then this change will affect the relationship quality among participants. From the results 
of this study, to enhance the relationship among participants, the contract designer should strengthen the contract coordination and adaptation provisions. In addition, the contract control function should be used with caution. Previous studies have confirmed that contract control exerts a significant effect on restricting opportunistic behavior [92]. However, the effect of improving contract control functions on relationship quality is uncertain. Participants must fully understand how much control provision they need in the contract design and use the contractual control provisions with caution.

6.3. Limitations and Future Research. Several limitations are present in this study. First, the empirical data used were all collected from megaprojects in China. Differences between the cultural characteristics and economic systems of other countries and those of China may lead to different research results. Second, this study utilized a self-reporting survey to collect information from one key respondent to represent the perspective of an organization, which is inevitably subject to the bias perceived by individuals. Third, one-time surveys were employed, which ignore the dynamic process of relationship quality formed in megaprojects. Future research should consider a longitudinal analysis to understand how relationship quality changes over time, particularly by identifying the events that cause changes.

\section{Data Availability}

The data used to support the findings of this study are available from the corresponding author upon request.

\section{Conflicts of Interest}

The authors declare that there are no conflicts of interest regarding the publication of this paper.

\section{Acknowledgments}

The study is supported by the Co-innovation Center of Green Building subject (X18007S) and the Humanities and Social Sciences Research Program of Universities in Shandong (J18RA062).

\section{References}

[1] B. Flyvbjerg, "What you should know about megaprojects and why: an overview," Project Management Journal, vol. 45, no. 2, pp. 6-19, 2014.

[2] R. G. Little, "The emerging role of public-private partnerships in megaproject delivery," Public Works Management and Policy, vol. 16, no. 3, pp. 240-249, 2011.

[3] B. Flyvbjerg, N. Bruzelius, and W. Rothengatter, Megaprojects and Risk: An Anatomy of Ambition, Cambridge University Press, Cambridge, UK, 2003.

[4] Y. Hu, A. P. C. Chan, Y. Le et al., "From construction megaproject management to complex project management: bibliographic analysis," Journal of Management in Engineering, vol. 31, no. 4, article 04014052, 2013.
[5] N. J. Brookes and G. Locatelli, "Power plants as megaprojects: using empirics to shape policy, planning, and construction management," Utilities Policy, vol. 36, pp. 57-66, 2015.

[6] I. Kardes, A. Ozturk, S. T. Cavusgil, and E. Cavusgil, "Managing global megaprojects: complexity and risk management," International Business Review, vol. 22, no. 6, pp. 905-917, 2013.

[7] B. Flyvbjerg, Over Budget, Over Time, Over and Over Again: Managing Major Projects, Oxford University Press, Oxford, UK, 2011.

[8] J. Eweje, R. Turner, and R. Müller, "Maximizing strategic value from megaprojects: the influence of information-feed on decision-making by the project manager," International Journal of Project Management, vol. 30, no. 6, pp. 639-651, 2012.

[9] R. Miller and D. R. Lessard, The Strategic Management of Large Engineering Projects: Shaping Institutions, Risks, and Governance, MIT Press, Cambridge, MA, USA, 2001.

[10] A. Mazur, A. Pisarski, A. Chang, and N. M. Ashkanasy, "Rating defence major project success: the role of personal attributes and stakeholder relationships," International Journal of Project Management, vol. 32, no. 6, pp. 944-957, 2014.

[11] J. A. Drexler Jr. and E. W. Larson, "Partnering: why project owner-contractor relationships change," Journal of Construction Engineering and Management, vol. 126, no. 4, pp. 293-297, 2000.

[12] X. Meng, "The effect of relationship management on project performance in construction," International Journal of Project Management, vol. 30, no. 2, pp. 188-198, 2012.

[13] E. Radziszewska-Zielina and B. Szewczyk, "Supporting partnering relation management in the implementation of construction projects using AHP and fuzzy AHP methods," Procedia Engineering, vol. 161, pp. 1096-1100, 2016.

[14] E. Radziszewska-Zielina, "Assessment methods of partnering relations of Polish, Slovak and Ukrainian construction enterprises with the use of fuzzy logic/metodyka oceny relacji partnerskich polskich, słowackich I ukrainskich przedsiebiorstw budowlanych z wykorzystaniem logiki rozmytej," Archives of Civil Engineering, vol. 57, no. 1, pp. 87-118, 2011.

[15] T.-T. Chen and T.-C. Wu, "Construction project partnering using fuzzy based decision making methodology," Journal of the Chinese Institute of Engineers, vol. 35, no. 3, pp. 269-284, 2012.

[16] S. O. Cheung, H. C. H. Suen, and K. K. W. Cheung, "An automated partnering monitoring system-Partnering Temperature Index," Automation in Construction, vol. 12, no. 3, pp. 331-345, 2003.

[17] J. F. Y. Yeung, A. P. C. Chan, and D. W. M. Chan, "A computerized model for measuring and benchmarking the partnering performance of construction projects," Automation in Construction, vol. 18, no. 8, pp. 1099-1113, 2009.

[18] R. Bayliss, S.-O. Cheung, H. C. H. Suen, and S.-P. Wong, "Effective partnering tools in construction: a case study on MTRC TKE contract 604 in Hong Kong," International Journal of Project Management, vol. 22, no. 3, pp. 253-263, 2004.

[19] L. Poppo and T. Zenger, "Do formal contracts and relational governance function as substitutes or complements?," Strategic Management Journal, vol. 23, no. 8, pp. 707-725, 2002.

[20] I. R. Macneil, "The new social contract: an inquiry into modern contractual relations," Ethics, vol. 93, no. 1, p. 168, 1982.

[21] T. Mellewigt, A. Madhok, and A. Weibel, "Trust and formal contracts in interorganizational relationships - substitutesand 
complements," Managerial and Decision Economics, vol. 28, no. 8, pp. 833-847, 2007.

[22] T. Mellewigt, C. Decker, and B. Eckhard, "What drives contract design in alliances? Taking stock and how to proceed," Zeitschrift für Betriebswirtschaft, vol. 82, no. 7-8, pp. 839-864, 2012.

[23] D. J. Schepker, W.-Y. Oh, A. Martynov, and L. Poppo, "The many futures of contracts," Journal of management, vol. 40, no. 1, pp. 193-225, 2014.

[24] J. You, Y. Chen, W. Wang, and C. Shi, "Uncertainty, opportunistic behavior, and governance in construction projects: the efficacy of contracts," International Journal of Project Management, vol. 36, no. 5, pp. 795-807, 2018.

[25] X. Wang and L. Liu, "Cultural barriers to the use of Western project management in Chinese enterprises: some empirical evidence from Yunnan province," Project Management Journal, vol. 38, no. 3, pp. 61-73, 2007.

[26] S. Y. Chou and T. Chang, "The Chinese supervisor's perspective of receiving unsolicited subordinate helping behaviour: a theoretical analysis," International Journal of Management Concepts and Philosophy, vol. 10, no. 4, pp. 445-462, 2017.

[27] C. C.-S. Kam and M. H. Bond, "Role of emotions and behavioural responses in mediating the impact of face loss on relationship deterioration: are Chinese more face-sensitive than Americans?," Asian Journal of Social Psychology, vol. 11, no. 2, pp. 175-184, 2008 .

[28] R. Atkinson, "Project management: cost, time and quality, two best guesses and a phenomenon, its time to accept other success criteria," International Journal of Project Management, vol. 17, no. 6, pp. 337-342, 1999.

[29] T. Cooke-Davies, "Return of the project managers," Management Today, vol. 119, 1990.

[30] A. u. Musawir, C. E. M. Serra, O. Zwikael, and I. Ali, "Project governance, benefit management, and project success: towards a framework for supporting organizational strategy implementation," International Journal of Project Management, vol. 35, no. 8, pp. 1658-1672, 2017.

[31] M. Winter, C. Smith, P. Morris, and S. Cicmil, "Directions for future research in project management: the main findings of a UK government-funded research network," International Journal of Project Management, vol. 24, no. 8, pp. 638-649, 2006.

[32] R. Müller and K. Jugdev, "Critical success factors in projects," International Journal of Managing Projects in Business, vol. 5, no. 4, pp. 757-775, 2012.

[33] P. Serrador and R. Turner, "The relationship between project success and project efficiency," Project Management Journal, vol. 46, no. 1, pp. 30-39, 2015.

[34] K. Khan, J. R. Turner, and T. Maqsood, "Factors that influence the success of public sector projects in Pakistan," in Proceedings of IRNOP 2013 Conference, pp. 17-19, Oslo, Norway, June 2013

[35] M. B. Jelodar, T. W. Yiu, and S. Wilkinson, "A conceptualisation of relationship quality in construction procurement," International Journal of Project Management, vol. 34, no. 6, pp. 997-1011, 2016.

[36] K. Roberts, S. Varki, and R. Brodie, "Measuring the quality of relationships in consumer services: an empirical study," $E \mathbf{U}$ ropean Journal of Marketing, vol. 37, no. 1-2, pp. 169-196, 2003.

[37] L. C. Leonidou, S. Samiee, B. Aykol, and M. A. Talias, "Antecedents and outcomes of exporter-importer relationship quality: synthesis, meta-analysis, and directions for further research," Journal of international marketing, vol. 22, no. 2, pp. 21-46, 2014.
[38] A. V. Marrewijk, S. R. Clegg, T. S. Pitsis et al., "Managing public-private megaprojects: Paradoxes, complexity, and project design," International Journal of Project Management, vol. 26, no. 6, pp. 591-600, 2008.

[39] P. Lu, S. Guo, L. Qian, P. He, and X. Xu, "The effectiveness of contractual and relational governances in construction projects in China," International Journal of Project Management, vol. 33, no. 1, pp. 212-222, 2015.

[40] X. Zheng, Y. Lu, Y. Le, Y. Li, and J. Fang, "Formation of interorganizational relational behavior in megaprojects: perspective of the extended theory of planned behavior," Journal of Management in Engineering, vol. 34, no. 1, p. 04017052, 2018.

[41] C. Black, A. Akintoye, and E. Fitzgerald, "An analysis of success factors and benefits of partnering in construction," International Journal of Project Management, vol. 18, no. 6, pp. 423-434, 2000.

[42] R. Cropanzano, E. L. Anthony, S. R. Daniels, and A. V. Hall, "Social exchange theory: a critical review with theoretical remedies," Academy of Management Annals, vol. 11, no. 1, pp. 479-516, 2017.

[43] R. M. Emerson, "Social exchange theory," Annual review of sociology, vol. 2, no. 1, pp. 335-362, 1976.

[44] K. S. Cook, C. Cheshire, E. R. Rice et al., "Social exchange theory," in Handbook of Social Psychology, pp. 61-88, Springer, Berlin, Germany, 2013.

[45] P. M. Blau, Exchange and Power in Social Life, Transaction Publishers, Piscataway, NJ, USA, 1964.

[46] X. Luo, "Trust production and privacy concerns on the Internet," Industrial Marketing Management, vol. 31, no. 2, pp. 111-118, 2002.

[47] R. Cropanzano and M. S. Mitchell, "Social exchange theory: an interdisciplinary review," Journal of Management, vol. 31, no. 6, pp. 874-900, 2005.

[48] S. K. Muthusamy and M. A. White, "Learning and knowledge transfer in strategic alliances: a social exchange view," Organization Studies, vol. 26, no. 3, pp. 415-441, 2005.

[49] A. Zaheer, B. Mcevily, and V. Perrone, "Does trust matter? Exploring the effects of interorganizational and interpersonal trust on performance," Organization Science, vol. 9, no. 2, pp. 141-159, 1998.

[50] M. Ng, "Examining social exchange among Chinese service workers," Asia-Pacific Journal of Business Administration, vol. 8, no. 2, pp. 163-176, 2016.

[51] F. Lumineau, "How contracts influence trust and distrust," Social Science Electronic Publishing, vol. 43, no. 5, pp. 15531577, 2014.

[52] M. P. Buvik and S. D. Tvedt, "The influence of project commitment and team commitment on the relationship between trust and knowledge sharing in project teams," Project Management Journal, vol. 48, no. 2, pp. 5-21, 2017.

[53] A. Madhok, "Revisiting multinational firms' tolerance for joint ventures: a trust-based approach," Journal of international Business Studies, vol. 37, no. 1, pp. 30-43, 2006.

[54] S. P. Wong and S. O. Cheung, "Trust in construction partnering: views from parties of the partnering dance," International Journal of Project Management, vol. 22, no. 6, pp. 437-446, 2004.

[55] H. Doloi, "Relational partnerships: the importance of communication, trust and confidence and joint risk management in achieving project success," Construction Management and Economics, vol. 27, no. 11, pp. 1099-1109, 2009.

[56] A. Falk and U. Fischbacher, "A theory of reciprocity," Games and Economic Behavior, vol. 54, no. 2, pp. 293-315, 2006. 
[57] E. Fehr and S. Gächter, "Fairness and retaliation: the economics of reciprocity," Journal of Economic Perspectives, vol. 14, no. 3, pp. 159-182, 2000.

[58] J. J. Han, G. H. Zhou, L. I. Yan-Lai et al., "On cooperative behavior in multi-participants project team based on reciprocity and altruism preferences," Journal of Systems and Management, vol. 20, no. 4, pp. 545-553, 2014.

[59] G.-D. Wu, "Project-based supply chain cooperative incentive based on reciprocity preference," International Journal of Simulation Modelling, vol. 13, no. 1, pp. 102-115, 2014.

[60] H. L. Angle and J. L. Perry, "An empirical assessment of organizational commitment and organizational effectiveness," Administrative science quarterly, vol. 26, no. 1, pp. 1-14, 1981.

[61] L. L. Berry and A. Parasuraman, Marketing services: Competing through Quality, Simon \& Schuster, New York, NY, USA, 2004.

[62] H. Emerson, J. Cook, H. Polatajko, and R. Segal, "Enjoyment experiences as described by persons with schizophrenia: a qualitative study," Canadian Journal of Occupational Therapy, vol. 65, no. 4, pp. 183-192, 1998.

[63] E. Anderson and B. Weitz, "Determinants of continuity in conventional industrial channel dyads," Marketing science, vol. 8, no. 4, pp. 310-323, 1989.

[64] C. J. F. Hung, "Cultural influence on relationship cultivation strategies: multinational companies in China," Journal of Communication Management, vol. 8, no. 3, pp. 264-281, 2004.

[65] Y. Paik and R. L. Tung, "Negotiating with east Asians: how to attain "Win-Win" outcomes," Mir Management International Review, vol. 39, no. 2, pp. 103-122, 1999.

[66] P. J. Buckley, J. Clegg, and H. Tan, "Cultural awareness in knowledge transfer to China-the role of guanxi and mianzi," in Foreign Direct Investment, China and the World Economy, pp. 165-191, Springer, Berlin, Germany, 2010.

[67] J. Child and Y. Lu, "Introduction: China and international enterprise," in Management Issues in China: International Enterprises, pp. 1-18, Routledge, London, UK, 1996.

[68] R. L. Tung and V. Worm, "Network capitalism: the role of human resources in penetrating the China market," International Journal of Human Resource Management, vol. 12, no. 4, pp. 517-534, 2001.

[69] T. M. Begley and W.-L. Tan, "The socio-cultural environment for entrepreneurship: a comparison between East Asian and Anglo-Saxon countries," Journal of International Business Studies, vol. 32, no. 3, pp. 537-553, 2001.

[70] N. Gao, Y. Chen, W. Wang, and Y. Wang, "Addressing project complexity: the role of contractual functions," Journal of Management in Engineering, vol. 34, no. 3, article 04018011, 2018.

[71] A. Y. Kwan and G. Ofori, "Chinese culture and successful implementation of partnering in Singapore's construction industry," Construction Management and Economics, vol. 19, no. 6, pp. 619-632, 2001.

[72] J. Sanderson, "Risk, uncertainty and governance in megaprojects: a critical discussion of alternative explanations," International Journal of Project Management, vol. 30, no. 4, pp. 432-443, 2012.

[73] F. Lumineau and D. Malhotra, "Shadow of the contract: how contract structure shapes interfirm dispute resolution," Strategic Management Journal, vol. 32, no. 5, pp. 532-555, 2011.

[74] F. Lumineau, "How contracts influence trust and distrust," Journal of management, vol. 43, no. 5, pp. 1553-1577, 2017.

[75] F. Lumineau and B. V. Quélin, "An empirical investigation of interorganizational opportunism and contracting mechanisms," Strategic Organization, vol. 10, no. 1, pp. 55-84, 2012.
[76] B. Huo, Y. Ye, and X. Zhao, "The impacts of trust and contracts on opportunism in the 3PL industry: the moderating role of demand uncertainty," International Journal of Production Economics, vol. 170, pp. 160-170, 2015.

[77] N. Argyres and K. J. Mayer, "Contract design as a firm capability: an integration of learning and transaction cost perspectives," Academy of Management Review, vol. 32, no. 4, pp. 1060-1077, 2007.

[78] K. J. Mayer and N. S. Argyres, "Learning to contract: evidence from the personal computer industry," Organization Science, vol. 15, no. 4, pp. 394-410, 2004.

[79] P. W. L. Vlaar, F. A. J. Van den Bosch, and H. W. Volberda, "On the evolution of trust, distrust, and formal coordination and control in interorganizational relationships," Group and Organization Management, vol. 32, no. 4, pp. 407-428, 2007.

[80] K. N. Jha and K. C. Iyer, "Commitment, coordination, competence and the iron triangle," International Journal of Project Management, vol. 25, no. 5, pp. 527-540, 2007.

[81] D. Malhotra and F. Lumineau, "Trust and collaboration in the aftermath of conflict: the effects of contract structure," Academy of Management Journal, vol. 54, no. 5, pp. 981-998, 2011.

[82] Y. Luo, "Contract, cooperation, and performance in international joint ventures," Strategic Management Journal, vol. 23, no. 10, pp. 903-919, 2002.

[83] N. S. Argyres, J. Bercovitz, and K. J. Mayer, "Complementarity and evolution of contractual provisions: an empirical study of IT services contracts," Organization Science, vol. 18, no. 1, pp. 3-19, 2007.

[84] M. J. Zbaracki and M. Bergen, "When truces collapse: a longitudinal study of price-adjustment routines," Organization Science, vol. 21, no. 5, pp. 955-972, 2010.

[85] J. F. Hair Jr., G. T. M. Hult, C. Ringle et al., A primer on partial least squares structural equation modeling (PLS-SEM), Sage Publications, Thousand Oaks, CA, USA, 2016.

[86] P. T. Chow, S. O. Cheung, and K. Y. Chan, "Trust-building in construction contracting: mechanism and expectation," International Journal of Project Management, vol. 30, no. 8, pp. 927-937, 2012.

[87] J. K. Pinto, D. P. Slevin, and B. English, "Trust in projects: an empirical assessment of owner/contractor relationships," International Journal of Project Management, vol. 27, no. 6, pp. 638-648, 2009.

[88] F. T. Mavondo and E. M. Rodrigo, "The effect of relationship dimensions on interpersonal and interorganizational commitment in organizations conducting business between Australia and China," Journal of Business Research, vol. 52, no. 2, pp. 111-121, 2001.

[89] I.-L. Wu, C.-H. Chuang, and C.-H. Hsu, "Information sharing and collaborative behaviors in enabling supply chain performance: a social exchange perspective," International Journal of Production Economics, vol. 148, pp. 122-132, 2014.

[90] D. Y. Lee and P. L. Dawes, "Guanxi, trust, and long-term orientation in Chinese business markets," Journal of International Marketing, vol. 13, no. 2, pp. 28-56, 2005.

[91] L. E. Bygballe, A. R. Swärd, and A. L. Vaagaasar, "Coordinating in construction projects and the emergence of synchronized readiness," International Journal of Project Management, vol. 34, no. 8, pp. 1479-1492, 2016.

[92] E. Xie, J. Liang, and K. Z. Zhou, "How to enhance supplier performance in China: an integrative view of partner selection and partner control," Industrial Marketing Management, vol. 56, pp. 156-166, 2016. 


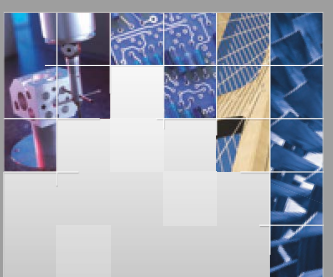

\section{Enfincering}
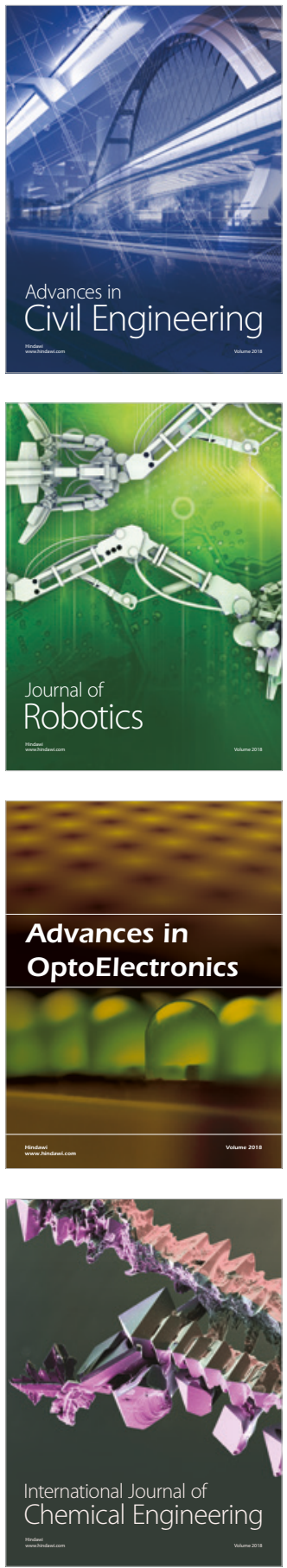

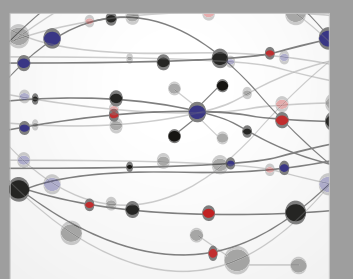

\section{Rotating \\ Machinery}

The Scientific World Journal

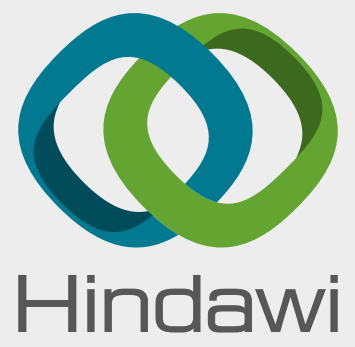

Submit your manuscripts at

www.hindawi.com
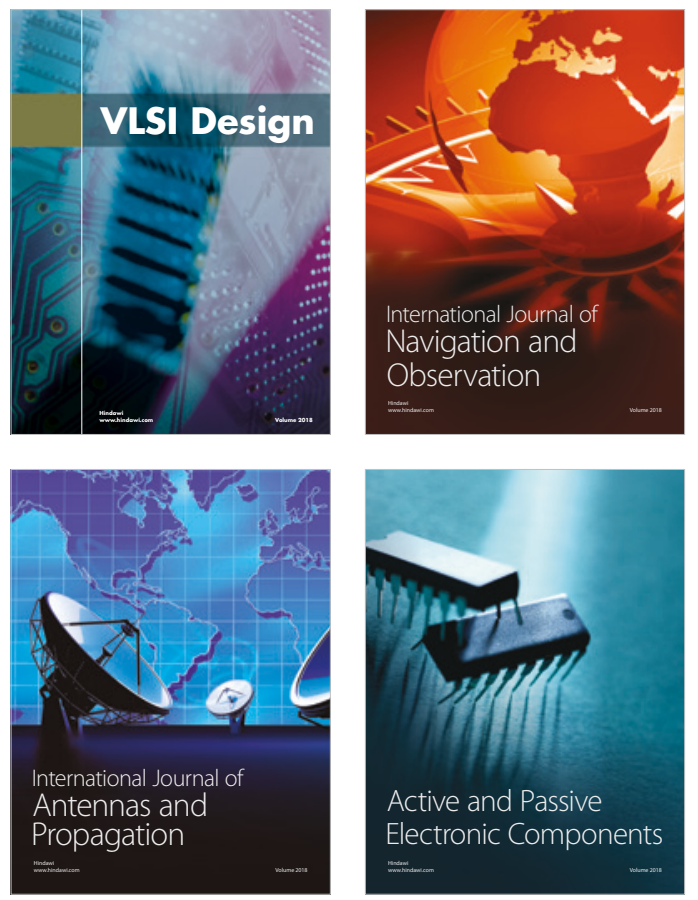
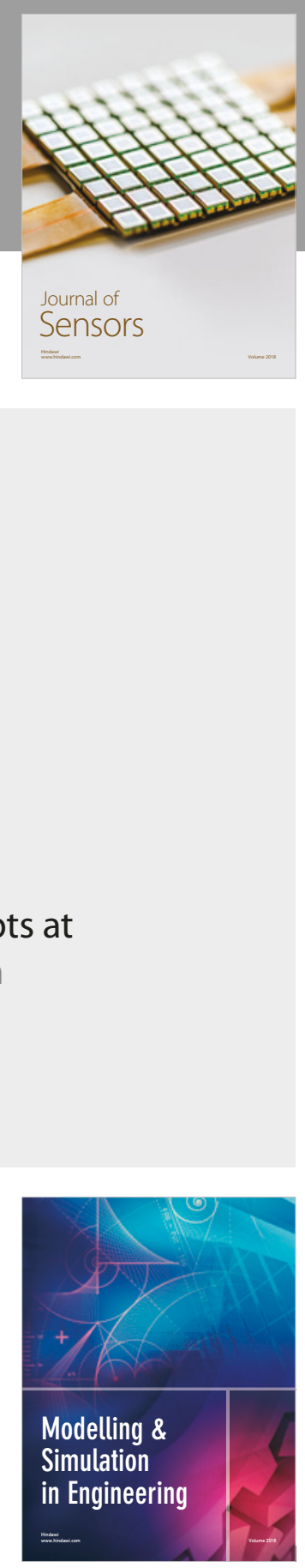

\section{Advances \\ Multimedia}
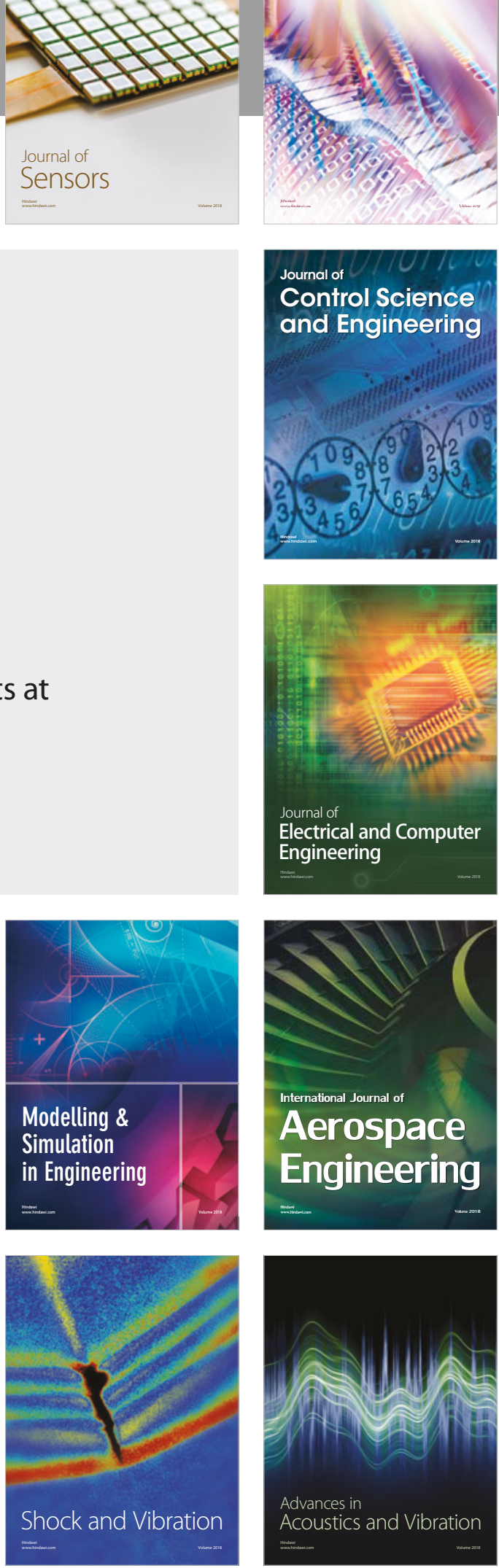